\title{
Approach-avoidance goals and relationship problems, communication of stress, and dyadic coping in couples
}

\author{
Monika Kuster $^{1} \cdot$ Sabine Backes $^{1} \cdot$ Veronika Brandstätter $^{1}{ }^{10} \cdot$ Fridtjof W. Nussbeck $^{2}$ \\ Thomas N. Bradbury ${ }^{3} \cdot$ Dorothee Sutter-Stickel $^{4} \cdot$ Guy Bodenmann $^{4}$
}

\begin{abstract}
Partners in romantic relationships differ in the extent to which they are oriented towards positive outcomes (e.g., intimacy) or away from negative outcomes (e.g., conflict). The present study examines these approach-avoidance relationship goals in relation to self-reported relationship problems, stress communication, and dyadic coping. Hypotheses were tested on a dyadic level (Actor-Partner Interdependence Model) using data from 368 couples. As expected, people endorsing approach goals reported fewer relationship problems, more effective stress communication, and better dyadic coping. People endorsing avoidance goals reported more relationship problems and poorer dyadic coping. Further, approach-oriented people tended to perceive their partner as being more communicative and more supportive, whereas avoidance-oriented people tended to perceive their partner as more communicative but less supportive. Reports by partners agreed with the self-reports of approach- and avoidance-oriented spouses concerning stress communication and dyadic coping. These findings highlight motivational factors in general, and orientation towards approach-avoidance goals in particular, as key features in understanding relationship maintenance.
\end{abstract}

Veronika Brandstätter

v.brandstaetter@psychologie.uzh.ch

1 Department of Psychology - Psychology of Motivation, Volition, and Emotion, University of Zurich, Binzmühlestr. 14/6, 8050 Zurich, Switzerland

2 Department of Psychology, Psychological Methods and Evaluation, Bielefeld University, Bielefeld, Germany

3 Department of Psychology - Clinical Psychology, University of California, Los Angeles, USA

4 Department of Psychology - Clinical Psychology for Children/Adolescents, and Couples/Families, University of Zurich, Zurich, Switzerland
Keywords Approach-avoidance goals · Relationship problems $\cdot$ Stress communication $\cdot$ Dyadic coping $\cdot$ Close relationships

\section{Introduction}

In view of growing evidence that relationship problems, inadequate communication of stress, and deficient dyadic coping all compromise the quality and stability of intimate relationships (e.g., Bodenmann and Cina 2005; Herzberg 2013; Papp and Witt 2010), important new questions are emerging about why some couples are more vulnerable than others to these effects. Individual differences, especially in goal-related and motivational processes, have not received much attention so far as antecedent conditions of relationship problems, stress communication, and dyadic coping, but seem highly relevant because of their pervasive effect on cognition, affect, and behaviour. People's fundamental motivational orientations (i.e., approach vs. avoidance) have a powerful impact on their intimate relationships (Gable and Impett 2012). More specifically, approach relationship goals (i.e., goals focusing on the pursuit of positive experiences in one's relationship, such as closeness, growth, and intimacy) and avoidance relationship goals (i.e., goals focusing on avoiding negative experiences, such as disagreement and conflict) have been associated with specific cognitive, emotional, and behavioural processes in close relationships that ultimately impact the partners' satisfaction with their relationship (see Gable and Berkman 2008 for a review; Kuster et al. 2015). To date, however, studies focusing on approach and avoidance relationship goals have mainly investigated their impact on such broad concepts as relationship satisfaction (Impett et al. 2010; for an exception see Kuster et al. 2015), leaving several more specific aspects of relationship 
functioning unaddressed. In this study, we focus on relationship problems, the inadequate communication of stress, and deficient dyadic coping because these factors are among the most influential when it comes to relationship functioning: Relationship problems are known to undermine relationships (e.g., Gottman 1994,), for example, whereas stress and communication are among the most influential aspects concerning relationships (e.g., Randall and Bodenmann 2009; Story and Bradbury 2004; Woodin 2011), and dyadic coping can be understood as one example of the dyadic coping behaviour that couples engage in to overcome challenges posed by stress (Bodenmann 1997, 2005).

Below, we will focus on approach and avoidance relationship goals and hypothesize that the degree to which both partners experience relationship problems, communicate with their partner about stress, or try to cope with stress depends on their respective approach and avoidance goals.

\section{Approach-avoidance goals and their specific cognitive, affective, and behavioural correlates in close relationships}

Approach and avoidance orientation are commonly viewed as distinct and independent motivational systems and represent one of the most fundamental distinctions for explaining human behaviour (Carver et al. 2000; Elliot 2008; Higgins 2011). Approach orientation promotes movement towards desired end states, whereas avoidance orientation increases movement away from undesired end states (Elliot 2008; Elliot and Thrash 2002; Gray 1990). Recent work has applied this approach-avoidance distinction to interpersonal goals (Gable 2006), which are more context-sensitive than traits. Studies examining the effects of approach-avoidance goals on the satisfaction of partners in intimate relationships demonstrate, for example, that a strong approach orientation predicts higher levels of relationship satisfaction and reduces feelings of loneliness. In contrast to this, a strong avoidance orientation is associated with reduced relationship satisfaction, more feelings of loneliness and relationship insecurity, in both women and men (Gable 2006; Impett et al. 2010).

Some studies have focused on how approach-avoidance orientation and goals influence relationship satisfaction (Gable and Berkman 2008; Gable and Poore 2008; Impett et al. 2010; Updegraff et al. 2004). Approach goals are associated with an increased experience of daily positive affect, which in turn enhances feelings of satisfaction and feelings of closeness to the partner (Impett et al. 2010). Approach orientation as a trait is also related to an increased proactive initiation of positive social events (Gable et al. 2000). Avoidance goals, on the other hand, correspond to higher reactivity to negative social events: when negative social events occur, individuals with pronounced avoidance goals rate them as being more important than those individuals with few avoidance goals (Elliot et al. 2006; Gable 2006; Gable et al. 2000). Moreover, highly avoidance-oriented individuals are sensitive to threats and react readily to them, leaving them in a permanently vigilant state (Gable et al. 2000). A recent study showed that the focus on negative events exhibited by avoidance-oriented spouses leads to the escalation of negative communication (Kuster et al. 2015). Finally, the stronger people's approach goals are, the more responsive outside observers rate them as being to their partner's needs; with stronger avoidance goals, people are rated as being less responsive (Impett et al. 2010). Evidently, approach and avoidance goals affect cognitive processes such as memory, the interpretation of ambiguous information and affective cues as well as the way spouses interact (Derryberry and Reed 1994; Elliot and McGregor 1999; Gable and Poore 2008). Notably, studies that assessed both partners' approach and avoidance goals have not found gender-specific differences.

Based on this evidence, we view the distinction between approach and avoidance goals as being highly relevant to the way in which couples experience relationship problems, communicate stress, and cope together as a team. In this we follow Elliot, Thrash, and Murayama (2011), who stated that "specific types and properties of goals [i.e., approach vs. avoidance] that individuals pursue in their daily lives are of critical importance in understanding the why and the what of stress and coping" (p. 667). Demonstrating the supposed relationship between approach-avoidance goals and these factors in a dyadic study would lead to a better understanding of the dynamics of some of the most influential factors in intimate relationships, particularly because most studies on approach-avoidance relationship goals have been conducted with individuals (see Impett et al. 2010; Kuster et al. 2015 for exceptions). This is likely to be an important oversight in that partners influence each other and consequently their estimations depend on each other. Conducting dyadic studies is therefore essential in order to control for these dependencies. Otherwise it remains impossible to understand how exactly intimate relationships function or develop (e.g., Kenny et al. 2006).

\section{Approach-avoidance goals and relationship problems, stress communication, and dyadic coping}

\section{Approach-avoidance goals and relationship problems}

Relationship problems are defined as any form of emotional or problem-centred stress directly concerning the two members of a couple (e.g., conflict, partners' difficult temperaments, negotiations over interpersonal distance) and 
are known to impose strains upon intimate relationships (Bodenmann 1997; Randall and Bodenmann 2009; Story and Bradbury 2004). Approach-oriented individuals focus on rewarding outcomes, such as intimacy and validation, and are more attuned to opportunities to feel closer to each other (Gable et al. 2000). Roth and Cohen (1986) argue that approach orientation does not forestall threat and negative emotions, but rather facilitates the constructive resolution and assimilation of these experiences. Thus, because of their focus on constructiveness, highly approach-oriented people may be better at regulating relationship problems within their relationship. In contrast, a focus on negative outcomes or events, which is inherent in avoidance regulation, is likely to elicit and sustain threat appraisals, anxiety, and self-protection processes, as the individual is constantly reminded of aversive possibilities (Elliot and Church 1997; Elliot and Sheldon 1997). In the achievement context, Elliot and McGregor (1999) showed that individuals with performance-avoidance goals experienced more worry during an exam and therefore performed worse. Analogously, in the context of romantic relationships, avoidance-oriented people may focus more strongly on problems experienced within the relationship or on the likelihood of events that are adverse to the relationship. With this in mind, we expect that the more approach-oriented people are, the fewer relationship problems they will report, and the more avoidanceoriented people are, the more relationship problems they will report (Hypothesis 1).

\section{Approach-avoidance goals and perception of one's own and partner's communication of stress}

As conceptualized in our study, stress communication is about communicating stress experienced outside the relationship (e.g., challenges at work, conflict with a friend) to the partner. It is one aspect of self-disclosure (Bodenmann 1995), defined as the process of revealing personal information about oneself to one's partner (Derlega et al. 1993). Self-disclosure is associated with the quality and stability of close relationships, presumably because it can serve as an act of relationship maintenance (Sprecher and Hendrick 2004) and as a means of enhancing trust and intimacy (Bodenmann 2005). Approach-oriented spouses are especially attuned to these kinds of rewarding outcomes (i.e., intimacy and validation) and are more attuned to opportunities to feel closer to each other (Gable et al. 2000). At the same time, approachoriented people presumably recognize and acknowledge opportunities to enhance intimacy with their partners more easily, which clearly might apply to situations in which their partners communicate stress or ask for support.

However, self-disclosure also entails the potential risk of making oneself vulnerable to another person. The risk of opening up to another person and then being hurt, misunderstood, ignored or even rejected, may seem worse than the actual problem, at least to some individuals (Fisher et al. 1988; Harris et al. 1999). Goal orientation literature demonstrates that the more that individuals try to avoid situations involving the possibility of embarrassment or getting hurt, the less likely they are to ask others for help or advice (Butler 2007; Elliot et al. 2006). At the same time, goal orientation affects information processing and memory in such a way that avoidance-oriented individuals focus more strongly on negative events, give greater weight to emotions concerning feelings of insecurity, and recall negative information better (Gable and Poore 2008; Strachman and Gable 2006; Updegraff et al. 2004). With that in mind, we first expect that the more approach-oriented people are, the more they will report communicating their stress and negative feelings to their partner, whereas the more avoidanceoriented people are, the less likely it is that they will report communicating stress-relevant information to their partner (Hypothesis 2a). Moreover, because of their being attuned to opportunities for enhancing intimacy, we expect that the more approach-oriented people are, the more stress communication they ascribe to their partner. The same should be true of avoidance-oriented people, because of their heightened sensitivity for negative information (Hypothesis 2b).

\section{Approach-avoidance goals and perception of one's own and partner's dyadic coping}

Dyadic coping, or the dyadic process by which one partner responds supportively to the other partner's stress signals by validating the partner's feelings, giving advice, or providing practical support, is a robust predictor of relationship quality and stability (see Bodenmann 2005, for an overview; Falconier et al. 2015; Herzberg 2013). The extent to which partners' exchanges convey mutual understanding, validation, and caring determines the experience of intimacy (intimacy process model; Reis and Patrick 1996). Intimacy-enhancing behaviour can be described as the experienced availability of advice and information, or the knowledge that the partner can be trusted to provide help (Cutrona 2004). Approachoriented spouses are sensitive to the possibility of enhancing intimacy within their relationship and proactively initiate positive social interactions (Gable and Impett 2012), and we expect that providing or exchanging mutual support is one way of doing this. At the same time, approach-oriented people presumably recognize their partners' attempts to provide support more easily.

Avoidance-oriented spouses, on the other hand, are sensitive to events that could harm the relationship (Gable and Berkman 2008), including stress, discussing a conflict, or dealing with negative influences on the relationship in general. Concurrently, they are said to be less responsive in social interactions (Impett et al. 2010). With that in mind, we 
Fig. 1 Actor-Partner Interdependence Model (Kenny et al. 2006) depicting approachavoidance goals and different outcome variables (relationship problems, self-reported and partner-reported stress communication, and self-reported and partner-reported dyadic coping). The path coefficients are set equal between partners (e.g., $\left.\mathrm{a}_{\mathrm{A} 1=} \mathrm{a}_{\mathrm{A} 2}\right)$

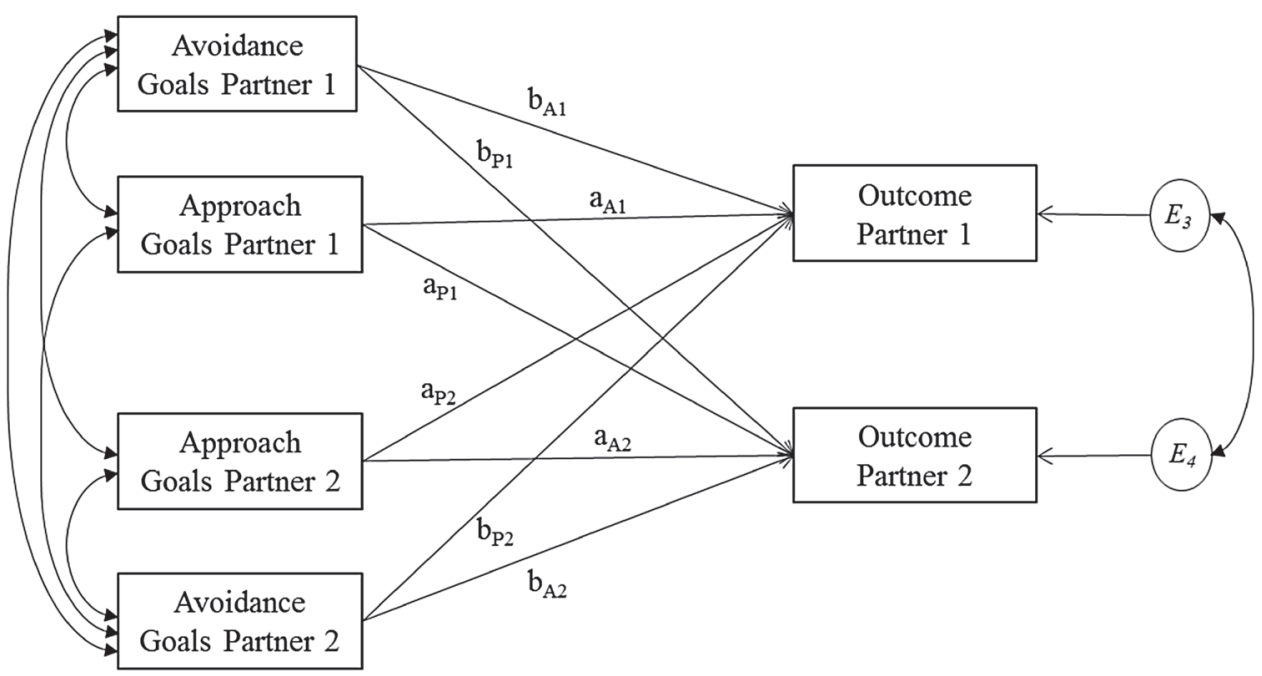

first hypothesize that the more approach-oriented people are, the more they will provide dyadic coping to their partner, and the more avoidance-oriented people are, the less likely they are to provide dyadic coping to their partner (Hypothesis 3a). Second, the more approach-oriented people are, the more dyadic coping they ascribe to their partner, and the more avoidance-oriented people are the less dyadic coping they ascribe to their partner (Hypotheses 3b).

\section{Approach-avoidance goals and the possible influence on the evaluation of one's own and the partner's stress communication and dyadic coping}

Studying both partners of a couple enables researchers to disentangle the effects that predictor variables assessed in both partners have on the outcome variables of either partner. This provides an important understanding about relationship issues (cf. Kenny et al. 2006). We want to take this a step further: In addition to analysing so-called partner effects included in the Actor-Partner Interdependence Model (APIM; Kenny et al. 2006), for example the extent to which one partner's goal orientation influences the other partner's stress communication, we are interested in how one partner evaluates the other's behaviour, i.e. the stress communication and dyadic coping provided by the partner. In the context of a dyadic study, these effects are especially intriguing. When we know the approach and avoidance goals of Partner 1 (see Fig. 1) and we ask Partner 1 to rate Partner 2's behaviour (Outcome Partner 1), the regression of the evaluation of Partner 2's behaviour by Partner 1 on Partner 2's goal orientation will be statistically free of unwanted perceptual biases because Partner 1's approach and avoidance goals serve as control variables. Goal orientation influences how the environment is experienced and interpreted (Gable and Poore 2008; Strachman and Gable 2006; Updegraff et al. 2004). Thus, we have to assume that
Partner 1's evaluation of Partner 2's stress communication and dyadic coping behaviour is biased by Partner 1's own approach and avoidance goals. Due to the specific paths in the APIM, it controls for this possible bias, offering the opportunity to examine without rater bias the extent to which approach-avoidance relationship goals are reflected in interpersonal behaviour. We therefore expect that the more approach-oriented people are, the more stress communication and dyadic coping is ascribed to them by their partners, and the more avoidance-oriented people are, the less stress communication and dyadic coping is ascribed to them by their partners (Hypotheses $2 \mathrm{c}$ and $3 \mathrm{c}$ ). A summary overview of the hypotheses is shown in Table 1.

\section{Method}

\section{Participants and procedure}

A total of 368 German-speaking, heterosexual couples participated in the present study. ${ }^{1}$ To be eligible, couples had to have been in their current relationship for at least 1 year. Of these couples, 244 couples were married $(66.3 \%)$ and 239 couples had children $(64.9 \%)$. The mean age of the women was 47 years $(S D=18.47)$ and of the men 49

\footnotetext{
${ }^{1}$ In order to determine the necessary sample size for detecting the postulated effects of the proposed research questions, the most complex analysis with the smallest effects was tested using a Structural Equation Model (SEM). Required sample sizes in SEMs can be determined by relying on Monte-Carlo studies (Muthén and Muthén 2002). In order to predefine the SEM, all model parameters have to be known a priori. Hancock (2006) identified an $N=300$ to be potentially sufficient to have enough power $(80 \%)$ to critically test the overall model fit against an RMSEA $=0.02$ if the model has more than 60 degrees of freedom $(d f)$.
} 
Table 1 Summary overview of all hypotheses

\begin{tabular}{|c|c|c|}
\hline Hypotheses & Path effects & Self-/partner-report \\
\hline \multicolumn{3}{|l|}{ Relationship problems } \\
\hline $\begin{array}{l}\text { H1: The more approach-oriented people are, the less relationship problems they will report, and the more } \\
\text { avoidance-oriented people are, the more relationship problems they will report }\end{array}$ & Actor & Self \\
\hline \multicolumn{3}{|l|}{ Own stress communication (first model) } \\
\hline $\begin{array}{l}\text { H2a: The more approach-oriented people are, the more they will report to communicate their stress to their } \\
\text { partner, and the more avoidance-oriented people are, the less likely it is that they will communicate stress- } \\
\text { relevant information to their partner }\end{array}$ & Actor & Self \\
\hline \multicolumn{3}{|l|}{ Partner's stress communication (second model) } \\
\hline $\begin{array}{l}\mathrm{H} 2 \mathrm{~b} \text { : The more approach-oriented people are as well as the more avoidance-oriented people are, the more } \\
\text { stress communication they ascribe to their partner }\end{array}$ & Actor & Partner \\
\hline $\begin{array}{l}\text { H2c: The more approach-oriented people are, the more stress communication is ascribed to them by their } \\
\text { partners, and the more avoidance-oriented people are, the less stress communication is ascribed to them by } \\
\text { their partners }\end{array}$ & Partner & Partner \\
\hline \multicolumn{3}{|l|}{ Own dyadic coping (first model) } \\
\hline $\begin{array}{l}\text { H3a: The more approach-oriented people are, the more they will provide dyadic coping to their partner, and } \\
\text { the more avoidance-oriented people are, the less likely they are to provide dyadic coping to their partner }\end{array}$ & Actor & Self \\
\hline \multicolumn{3}{|l|}{ Partner's dyadic coping (second model) } \\
\hline $\begin{array}{l}\text { H3b: The more approach-oriented people are, the more dyadic coping they ascribe to their partner, and the } \\
\text { more avoidance-oriented people are, the less likely they are to ascribe dyadic coping to their partner }\end{array}$ & Actor & Partner \\
\hline $\begin{array}{l}\text { H3c: The more approach-oriented people are, the more dyadic coping is ascribed to them by their partners, } \\
\text { and the more avoidance-oriented people are, the less dyadic coping is ascribed to them by their partners }\end{array}$ & Partner & Partner \\
\hline
\end{tabular}

years $(S D=18.33)$. The mean relationship duration was 21 years $(S D=17.97$; ranging from 1 to 60 years). In terms of the highest level of education completed, $6 \%$ of women had only attended mandatory school (9 years), $40 \%$ had completed vocational training, $21 \%$ had completed high school, and $32 \%$ had completed college or university. In the case of the men, $3 \%$ had attended mandatory school (9 years), 35\% had completed vocational training, $13 \%$ had completed high school, and $49 \%$ had an academic degree.

The study was advertised in newspapers and on the radio as a study looking at the impact of stress on relationship development in couples. Interested couples phoned in and were informed about the study procedure. Participants were first asked to complete a set of self-report measures at home before they came to our laboratory. They were instructed to complete the questionnaires independently of their partner. At the laboratory, couples were given more specific information about the session and both partners had to sign the consent form in order to continue. Subsequently, each spouse was escorted to a separate room where they completed three sets of questionnaires. Partners then participated together in several videotaped interactions. ${ }^{2}$ Finally, both partners were separated again for the last set of questionnaires before being

\footnotetext{
${ }^{2}$ Data presented in this paper are part of a large-scale study addressing different research subjects (Kuster et al. 2015; Landis et al. 2014; Zemp et al. 2016a, b). The present findings have no overlap with previously reported results.
}

debriefed and receiving a financial remuneration equalling approximately $\$ 108$. The procedure was evaluated and approved by the local ethics committee.

\section{Measures}

Approach and avoidance goals were assessed using an eightitem measure originally developed by Elliot et al. (2006) for use in the more general context of close relationships (e.g., friendships), and later adapted for romantic relationships (Gable 2006; Impett et al. 2008). Participants responded to items such as "I will be trying to deepen my relationship with my partner" (approach relationship goals; four items; $M=6.07, S D=0.84$, Cronbach's $\alpha=.73$ for women, and $M=5.88, S D=0.85$, Cronbach's $\alpha=.75$ for men) and "I will be trying to avoid disagreements and conflicts with my romantic partner" (avoidance relationship goals; four items; $M=4.89, S D=1.47$, Cronbach's $\alpha=.76$ for women, and $M=5.06, S D=1.32$, Cronbach's $\alpha=.73$ for men) on a 7 -point scale $(1=$ strongly disagree to $7=$ strongly agree $)$. The correlation between approach and avoidance goals was $r=.30(p<.01)$ for women and $r=.36(p<.01)$ for men, which is in line with previous studies (Elliot et al. 2006; Impett et al. 2010).

Relationship problems were assessed using the 9-item Multi-Dimensional Stress Questionnaire for Couples (MDSP; Bodenmann et al. 2008), which assesses the level of problems and stress of each individual in different relationshiprelated domains (e.g., conflicts with the partner, different 
Table 2 Descriptive statistics, correlations, and T-tests for women's and men's study variables

\begin{tabular}{|c|c|c|c|c|c|c|c|c|c|c|c|c|}
\hline & \multicolumn{2}{|l|}{ Women } & \multicolumn{2}{|l|}{ Men } & \multirow{2}{*}{$\begin{array}{l}\text { Difference (women-men) } \\
t_{d f=364}(d)\end{array}$} & \multicolumn{7}{|c|}{ Correlations } \\
\hline & $M(S D)$ & $\alpha$ & $M(S D)$ & $\alpha$ & & 1 & 2 & 3 & $4 a$ & $4 \mathrm{~b}$ & $5 \mathrm{a}$ & $5 b$ \\
\hline 1 Approach goals & $6.07(0.84)$ & .73 & $5.88(0.85)$ & .75 & $3.31 *(.23)$ & $.15^{*}$ & $.30 *$ & & & & & \\
\hline 2 Avoidance goals & 4.89 (1.47) & .76 & $5.06(1.32)$ & .73 & $-1.98(.12)$ & $.36^{*}$ & $.30 *$ & & & & & \\
\hline $\begin{array}{l}3 \text { Relationship prob- } \\
\text { lems }\end{array}$ & $1.67(0.54)$ & .84 & $1.58(0.47)$ & .83 & $3.25 *(.18)$ & & & $.47 *$ & $-.17 *$ & $-.14^{*}$ & $-.33^{*}$ & $-.55^{*}$ \\
\hline \multicolumn{13}{|l|}{ Stress communication } \\
\hline 4a Own & $3.68(0.74)$ & .79 & $3.06(0.76)$ & .75 & $11.44 *(.83)$ & & & -.08 & .07 & $.22 *$ & $.37 *$ & $.42 *$ \\
\hline 4b Partner's & $2.92(0.86)$ & .81 & $3.54(0.74)$ & .75 & $-10.72 *(.77)$ & & & -.11 & $.22 *$ & .06 & $.36^{*}$ & $.33^{*}$ \\
\hline \multicolumn{13}{|l|}{ Dyadic coping } \\
\hline 5a Own & $3.92(0.46)$ & .73 & $3.93(0.45)$ & .76 & $-0.54(.02)$ & & & $-.43 *$ & $.26^{*}$ & $.29 *$ & $.30 *$ & $.54^{*}$ \\
\hline 5b Partner's & $3.78(0.67)$ & .86 & $3.90(0.53)$ & .82 & $-3.53 *(.20)$ & & & $-.58^{*}$ & $.26^{*}$ & $.22 *$ & $.61 *$ & $.38 *$ \\
\hline
\end{tabular}

Applying the Bonferroni correction for multiple comparisons, we adjusted the critical alpha level for $t$ Tests for paired samples, *p $<.007$ (i.e., $.05 / 7)$. Correlation coefficients for women are above, for men below the diagonal, and between women and men along the diagonal (bold)

$M$ mean, $S D$ standard deviation, $\alpha$ Cronbach's alpha, $d f$ degrees of freedom, $d$ Cohen's $d$

values, difficult personality and/or behaviour of the partner) and external domains (e.g., job, children, finances, free time). All items were measured twice on a 4-point scale $(1=$ not at all to $4=$ very); once for the last 7 days, indicating acute problems or stress, and once for the last 12 months, indicating chronic problems or stress. In this study, we focused on acute relationship problems $(M=1.67, S D=0.54$, Cronbach's $\alpha=.84$ for women, and $M=1.58, S D=0.47$, Cronbach's $\alpha=.83$ for men), because (a) the measures of acute and chronic relationship problems strongly overlapped ( $r=.77$ for men, and $r=.73$ for women), (b) research on approach-avoidance goals has yet to demonstrate its longterm impact on relationship quality and problems and stress, and (c) because of the correlational structure of the data.

Stress communication was measured using a subscale of the Dyadic Coping Inventory (DCI; Bodenmann 2008) that focuses on how people communicate experienced stress (4 items; e.g., "I tell my partner when I'm stressed and need his emotional support"; $M=3.68, S D=0.74$, Cronbach's $\alpha=.79$ for women, and $M=3.06, S D=0.76$, Cronbach's $\alpha=.75$ for men) and how they perceive stress communication by their partner (4 items; e.g., "He/she tells me when he/she is stressed and needs my emotional support"; $M=2.92, S D=0.86$, Cronbach's $\alpha=.81$ for women, and $M=3.54, S D=0.74$, Cronbach's $\alpha=.75$ for men). All items are answered on a 5-point scale from $1=$ almost never to $5=$ very often and the subscales showed a good reliability, with Cronbach's $\alpha$ between .75, and .81 (see Table 2).

Dyadic coping was measured using another subscale of the Dyadic Coping Inventory (DCI; Bodenmann 2008), which assesses how frequently partners engage in certain types of coping behaviour by focusing on one's own behaviour (11 items; e.g., "I express to my partner that I am on his/her side" as an example for positive dyadic coping, "I do not take my partner's stress seriously" as an example for negative dyadic coping) and the evaluation of the partner's dyadic coping (11 items; e.g., "My partner displays empathy and understanding towards me", "When I'm stressed, my partner tends to withdraw"). All items were answered on a 5-point scale from $1=$ almost never to $5=$ very often. For the present study, positive and negative dyadic coping (reverse coded) were combined to form a total score, with higher scores indicating higher quality of dyadic coping (own dyadic coping: $M=3.92, S D=0.46$, Cronbach's $\alpha=$ .73 for women, and $M=3.93, S D=0.45$, Cronbach's $\alpha=$ .76 for men), and higher quality of dyadic coping of the partner $(M=3.78, S D=0.67$, Cronbach's $\alpha=.86$ for women, and $M=3.90, S D=0.53$, Cronbach's $\alpha=.82$ for men). All subscales displayed a good reliability, with Cronbach's $\alpha$ between .73, and .86 (see Table 2).

The descriptive statistics of the model variables (approach relationship goals, avoidance relationship goals, relationship problems, stress communication, and dyadic coping) and comparisons of women's and men's key variables are presented in Table 2. All in all, the couples that participated in our study reported rather low relationship problems as well as rather high own dyadic coping and dyadic coping on the part of the partner. Approach goals and avoidance goals were both positively related between partners, as was true of the level of relationship problems and dyadic coping. Relationship problems were negatively related to stress communication and dyadic coping in men and in women. Stress communication was positively related to dyadic coping in men and in women. Women reported significantly more approach relationship goals than men. Compared with men, women also reported higher levels of relationship problems, higher levels of own stress communication and lower levels of stress communication in their partners. Men reported 
significantly higher levels of dyadic coping in their female partners than women reported for their male partners.

\section{Data analysis plan}

In the current study, we assessed all variables for both members of each romantic couple to examine the effects of approach and avoidance relationship goals on relationship problems, stress communication, and dyadic coping. Additionally, both partners reported not only their own behaviour but also their perception of their partner's behaviour concerning stress communication and dyadic coping. The actor-partner interdependence model (APIM; Kenny et al. 2006) was used to assess the contribution of both partners' relationship goals. The APIM allows both the effect that a person's predictor variable has on his/her own criterion variable (known as actor effect; depicted $\mathrm{a}_{\mathrm{A} 1}, \mathrm{a}_{\mathrm{A} 2}, \mathrm{~b}_{\mathrm{A} 1}$, and $\mathrm{b}_{\mathrm{A} 2}$ in Fig. 1) to be estimated, and also the effect that a person's predictor variable has on the partner's criterion variable (known as partner effect; $a_{\mathrm{P} 1}, a_{\mathrm{P} 2}, b_{\mathrm{P} 1}$, and $b_{\mathrm{P} 2}$ in Fig. 1). To estimate actor and partner effects, we employed the structural equation modelling approach described by Kenny et al. (2006) using AMOS 20 (Arbuckle 2010). The APIM controls for the fact that data from two members of a couple are not independent (Kenny et al. 2006). Thus, actor and partner effects as well as the correlations between variables that are dependent on each other are estimated simultaneously in one model, controlling for each other and the dependency in the data.

As shown in Fig. 1, all models involve simultaneously testing four independent variables (his and her approach and avoidance relationship goals), and two outcome variables (his and her relationship problems, stress communication, and dyadic coping, and his and her evaluation of partner's stress communication and dyadic coping, respectively). The effects of one partner's approach and avoidance relationship goals on the outcome variables are not only controlled for each other but also for the effects of the other partner's effects. Since there are no clear-cut predictions within the existing literature concerning gender effects, we tested restrictive models in which path coefficients between the two partners of a dyad were treated as being equal (e.g., $\mathrm{a}_{\mathrm{A} 1}$ is equal to $\mathrm{a}_{\mathrm{A} 2}$; see Fig. 1$) .{ }^{3}$ First, we analysed the actor

\footnotetext{
${ }^{3}$ Although no hypotheses were formulated with respect to gender differences in model parameters, we explored these in supplementary analyses by analysing non-restricted models in which path coefficients were freely estimated. No relevant differences were found between model parameters as a function of gender. Compared with the reported model, only small differences of up to 0.05 occurred in the unstandardized path coefficients. The direction of the effect was always the same; the size of the parameter was virtually the same across gender.
}

and partner effects for the self-reported outcomes of both partners, i.e., relationship problems, own stress communication, and own dyadic coping (see Fig. 2a). Second, we analysed the actor and partner effects for the partner-reported outcomes. In these models, the actor effects represent the association between Partner 1's goal orientation and his/ her perception of Partner 2's behaviour, i.e., how Partner 1 perceives Partner 2's stress communication. The partner effects represent the association between Partner 1's goal orientation and the perception of Partner 2 of Partner 1's behaviour, i.e., Partner 2's perception of Partner 1's stress communication (see Fig. 2b). For stress communication and dyadic coping, we will report the results in the same order as used to describe the models: First, the models for own stress communication (own dyadic coping), then the models for the partner-reported stress communication (partner-reported dyadic coping). For every model, we will first present the significant results with regard to approach goals, followed by the significant results for avoidance goals. Non-significant effects are reported last.

\section{Results}

\section{Relationship problems}

We tested one model for relationship problems (Hypothesis 1). The model for relationship problems displayed a good fit in terms of the $\chi^{2}$ test and also with respect to additional model fit indices, $\chi^{2}(4)=9.316, p=.054, \mathrm{CFI}=.979$, $\mathrm{RMSEA}=.060$. Predicting relationship problems based on approach-avoidance goals explained 5\% of women's and $6 \%$ of men's variance in their relationship problems. All estimated effects are presented in Table 3. Please note that the explained variance $\left(\mathrm{R}^{2}\right)$ as well as standardized coefficients differ for men and women because we constrained unstandardized regression coefficients to be equal, but not the variances of predictors and residual variances of the outcome. Hence, the influence of the predictors are constrained to be equal across partners with respect to raw scores but do not necessarily have to be identical with respect to standardized scores. We did not impose restrictions on the standardized coefficients, as this would lead to a loss of the differences in explained variances, for example. The actor and partner effects from approach goals to own relationship problems $\left(\mathrm{a}_{\mathrm{A} 1}, \mathrm{a}_{\mathrm{A} 2}, \mathrm{a}_{\mathrm{P} 1}\right.$, and $\mathrm{a}_{\mathrm{P} 2}$; see Fig. 1) were negative and statistically significant, which means that the more approach-oriented participants were, the fewer relationship problems they reported and the fewer relationship problems their partners reported. The actor effects from avoidance goals to relationship problems $\left(\mathrm{b}_{\mathrm{A} 1}\right.$ and $b_{\mathrm{A} 2}$ ) were positive and statistically significant. In other words, the more avoidance-oriented participants were, the 
a

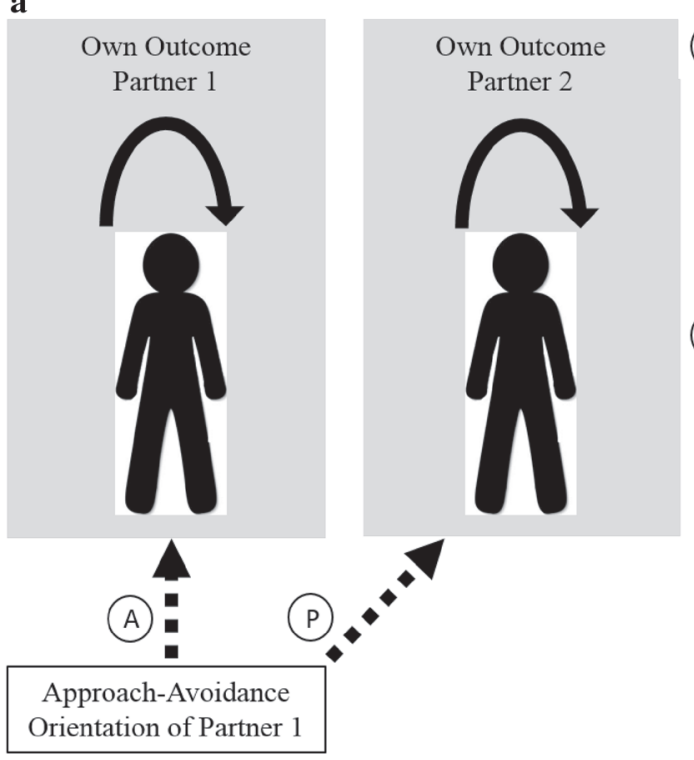

b

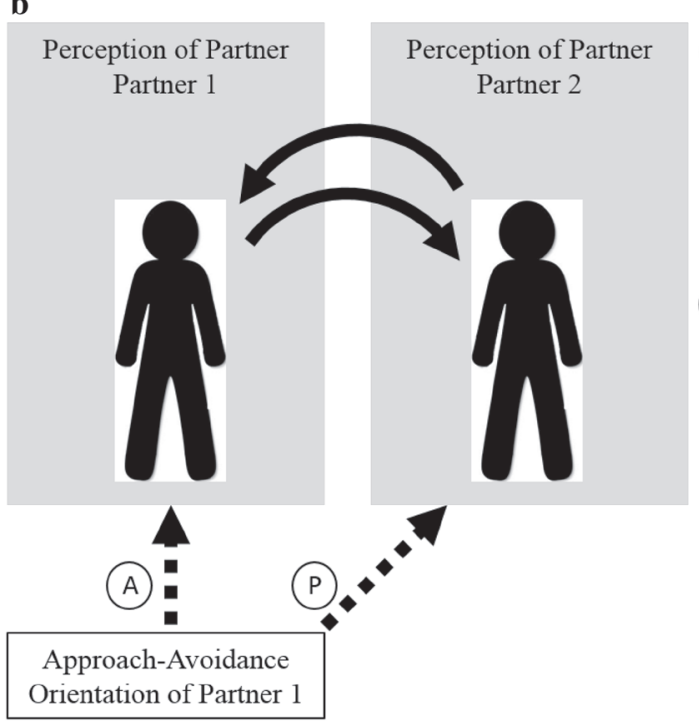

A Actor Effect of Self-Reported Data:

How is my goal orientation related to how I perceive
a) my relationship problems $(\mathrm{H} 1)$
b) my communication of stress (H2a)
c) how I support my partner (H3a)

\section{(P) Partner Effect of Self-Reported Data:}

How is my goal orientation related to how my partner perceives
a) his/her relationship prpoblems
b) his/her own communication of stress
c) how he/she supports me

Fig. 2 a To detect associations between Partner 1's goal orientation and $(A)$ the dependent variable of Partner 1 and $(P)$ the dependent variable of Partner 2, we first analysed the actor and partner effects with the self-reported outcomes (i.e., relationship problems, stress communication, and dyadic coping). b To detect associations

more relationship problems they reported. The partner effects from avoidance goals to relationship problems $\left(b_{\mathrm{P} 1}\right.$ and $b_{\mathrm{P} 2}$ ) were not significant. ${ }^{4}$

\footnotetext{
${ }^{4}$ Although we focused on acute relationship problems, we additionally tested the chronic relationship problems model. This model also displayed an excellent fit; $\chi^{2}(4)=2.536, p=.638, \mathrm{CFI}=1.000$, RMSEA $=.000$. Predicting relationship problems based on goal orientation (approach and avoidance) accounted for $4 \%$ of women's and $5 \%$ of men's variance in chronic relationship problems $(M=1.87$, $S D=0.53$, Cronbach's $\alpha=.83$ for women, and $M=1.76, S D=0.47$, Cronbach's $\alpha=.81$ for men). Compared with the reported model, the direction and size of all effects were virtually the same.
}

\section{A Actor Effect of Partner-Reported Data:}

How is my goal orientation related to how I perceive

a) my partner's communication of stress $(\mathrm{H} 2 \mathrm{~b})$

b) how he/she supports me (H3b)

\section{P Partner Effect of Partner-Reported Data:}

How is my goal orientation related to how my partner perceives

a) my communication of stress $(\mathrm{H} 2 \mathrm{c})$

b) how I support him/her (H3c) between Partner 1's goal orientation and (A) Partner 1's perception of the dependent variable of Partner 2 and $(P)$ Partner 2's perception of the dependent variable of Partner 1, we analysed the actor and partner effects with the partner-reported outcomes (i.e., stress communication and dyadic coping)

\section{Stress communication}

Two models were tested for stress communication. The first model tested the association between approach-avoidance goals and self-reporting of one's own stress communication (Hypothesis 2a). The second model tested the association between approach-avoidance goals and the level of stress communication which individuals ascribe to their partners (Hypothesis 2b) as well as the level of stress communication which their partners ascribe to them (Hypothesis 2c). Both models displayed an excellent fit; $\chi^{2}(4)=1.683, p=.794$, 
$\mathrm{CFI}=1.000, \mathrm{RMSEA}=.000$ for own, and $\chi^{2}(4)=3.453$, $p=.485, \mathrm{CFI}=1.000, \mathrm{RMSEA}=.000$ for the partner's stress communication. Predicting stress communication based on approach-avoidance goals explained 5\% of women's and $4 \%$ of men's variance in the first model and $5 \%$ of variance in women's and 3\% in men's variance in the second model. Effect estimates are presented in Table 3.

In the first model, the actor effects from approach goals to own stress communication $\left(\mathrm{a}_{\mathrm{A} 1}\right.$ and $\left.\mathrm{a}_{\mathrm{A} 2}\right)$ were positive and statistically significant, which means that the more approach-oriented participants were, the more likely they were to report communicating their stress to their partners. The actor effects from avoidance goals to own stress communication $\left(b_{\mathrm{A} 1}\right.$ and $\left.\mathrm{b}_{\mathrm{A} 2}\right)$ were negative and statistically significant, which means that the more avoidance-oriented participants were, the less they reported sharing perceived stress with their partners. The partner effects were not significant $\left(\mathrm{a}_{\mathrm{P} 1}, \mathrm{a}_{\mathrm{P} 2}, \mathrm{~b}_{\mathrm{P} 1}\right.$, and $\left.\mathrm{b}_{\mathrm{P} 2}\right)$.

In the second model, the actor and partner effects from approach goals to partner's stress communication $\left(\mathrm{a}_{\mathrm{A} 1}, \mathrm{a}_{\mathrm{A} 2}\right.$, $\mathrm{a}_{\mathrm{P} 1}$, and $\mathrm{a}_{\mathrm{P} 2}$ ) were positive and statistically significant. In other words, the more approach-oriented participants were, the more they described their partners as being communicative regarding their experienced stress, and the more their partners perceived them as being communicative regarding the experienced stress. The actor effects of avoidance goals to the partner's stress communication $\left(\mathrm{b}_{\mathrm{A} 1}\right.$ and $\left.\mathrm{b}_{\mathrm{A} 2}\right)$ were positive and marginally significant, which means that the more avoidance-oriented participants were, the more they described their partners as expressing experienced stress. The partner effects from avoidance goals to partner's stress communication $\left(\mathrm{b}_{\mathrm{P} 1}\right.$ and $\left.\mathrm{b}_{\mathrm{P} 2}\right)$ were negative and statistically significant. In other words, the more avoidance-oriented participants were, the less their partners perceived them as being communicative regarding their experienced stress.

\section{Dyadic coping}

Two models for dyadic coping were tested. The first model tested the association between approach-avoidance goals and one's own dyadic coping (Hypothesis 3a). The second model tested the association between approach-avoidance goals and level of dyadic coping that individuals ascribe to their partners (Hypothesis 3b) as well as the level of dyadic coping that their partners ascribe to them (Hypothesis $3 \mathrm{c}$ ). Both models display an excellent fit; $\chi^{2}(4)=2.095, p=.718$, $\mathrm{CFI}=1.000$, RMSEA $=.000$ for own and $\chi^{2}(4)=5.582$, $p=.233, \mathrm{CFI}=.994, \mathrm{RMSEA}=.033$ for the partner's dyadic coping. Predicting dyadic coping based on approach-avoidance goals explained $11 \%$ of women's and $12 \%$ of men's variance in the first model and $9 \%$ of women's and $14 \%$ of men's variance in the second model. Effect estimates are presented in Table 3.
In the first model, the actor and partner effects from approach goals to own dyadic coping $\left(\mathrm{a}_{\mathrm{A} 1}, \mathrm{a}_{\mathrm{A} 2}, \mathrm{a}_{\mathrm{P} 1}\right.$, and $\left.\mathrm{a}_{\mathrm{P} 2}\right)$ were positive and statistically significant, which means that the stronger approach goals participants hold, the more they report providing dyadic coping to their partners. Additionally, partners of more approach-oriented participants report providing more dyadic coping. The actor effects of avoidance goals $\left(\mathrm{b}_{\mathrm{A} 1}\right.$ and $\left.\mathrm{b}_{\mathrm{A} 2}\right)$ were not significant. However, the partner effects from avoidance goals to own dyadic coping $\left(b_{\mathrm{P} 1}\right.$ and $\left.b_{\mathrm{P} 2}\right)$ were negative and statistically significant. In other words, even though participants with stronger avoidance goals do not report providing less dyadic coping, partners of participants with stronger avoidance goals do report providing less dyadic coping.

In the second model, the actor and partner effects from approach goals to partner's dyadic coping $\left(\mathrm{a}_{\mathrm{A} 1}, \mathrm{a}_{\mathrm{A} 2}, \mathrm{a}_{\mathrm{P} 1}\right.$, and $\mathrm{a}_{\mathrm{P} 2}$ ) were positive and statistically significant, which means that the stronger approach goals participants hold, the more they perceive their partners as being supportive and the more they were perceived as being supportive by their partners. The actor and partner effects from avoidance goals to the partner's dyadic coping $\left(\mathrm{b}_{\mathrm{A} 1}, \mathrm{~b}_{\mathrm{A} 2}, \mathrm{~b}_{\mathrm{P} 1}\right.$, and $\left.\mathrm{b}_{\mathrm{P} 2}\right)$ were negative and statistically significant. In other words, the stronger avoidance goals participants hold, the less they perceive their partners as being supportive and the less they were perceived by their partners as being supportive.

\section{Discussion}

Couples vary widely in the way they perceive and manage problems and demands within their relationships. While differences in supportive interaction have until now largely been viewed in terms of (malleable) skill deficits, in the present paper we adopt a motivational point of view by focusing on individual differences in the spouses' approach and avoidance relationship goals. We expected the experience of relationship problems and different ways of managing stress within relationships (i.e., stress communication, dyadic coping) to be related to underlying goal orientations. To test these relations, we assessed both members of romantic couples to account for the interdependent nature of these relationship variables. Our models enabled us to test the influence of both goal types, whereby the influence of approach goals was controlled by avoidance goals and vice versa. For stress communication and dyadic coping, the analyses included reports about one's own as well as one's partner's behaviour. Furthermore, our large study sample provides a broad variety in relationship duration and age, which extends the existing literature beyond the emphasis on student samples and young couples (e.g., Impett et al. 2010). Our results show that approach and avoidance goal orientation, as a cognitive representation of desired or undesired 
Table 3 Effect estimates for the actor-partner interdependence models

\begin{tabular}{|c|c|c|c|c|c|}
\hline Model & Unstand. estimate & SE & $p$ & $\begin{array}{l}\text { Stand. estimate } \\
\text { women/men }\end{array}$ & $\mathrm{CI}_{95}$ lower/upper \\
\hline \multicolumn{6}{|l|}{ Relationship problems } \\
\hline \multicolumn{6}{|l|}{ Approach } \\
\hline \multicolumn{6}{|l|}{ H1 } \\
\hline Actor effect $\left(\mathrm{a}_{\mathrm{A} 1} ; \mathrm{a}_{\mathrm{A} 2}\right)$ & -.10 & .02 & $<.001$ & $-.15 /-.17$ & $-.05 /-.14$ \\
\hline Partner effect $\left(\mathrm{a}_{\mathrm{P} 1} ; \mathrm{a}_{\mathrm{P} 2}\right)$ & -.09 & .02 & $<.001$ & $-.15 /-.16$ & $-.05 /-.14$ \\
\hline \multicolumn{6}{|l|}{ Avoidance } \\
\hline \multicolumn{6}{|l|}{ H1 } \\
\hline Actor effect $\left(\mathrm{b}_{\mathrm{A} 1} ; \mathrm{b}_{\mathrm{A} 2}\right)$ & .04 & .01 & .002 & $.12 / .12$ & $.01 / .07$ \\
\hline Partner effect $\left(\mathrm{b}_{\mathrm{P} 1} ; \mathrm{b}_{\mathrm{P} 2}\right)$ & .02 & .01 & .124 & $.06 / .05$ & $-.01 / .05$ \\
\hline$R_{\text {Women }}^{2} / R_{\text {Men }}^{2}$ & $.05 / .06$ & & & & \\
\hline \multicolumn{6}{|c|}{ Own stress communication (first model) } \\
\hline \multicolumn{6}{|c|}{ Approach } \\
\hline \multicolumn{6}{|l|}{$\mathrm{H} 2 \mathrm{a}$} \\
\hline Actor effect $\left(\mathrm{a}_{\mathrm{A} 1} ; \mathrm{a}_{\mathrm{A} 2}\right)$ & .16 & .03 & $<.001$ & $.18 / .17$ & $.09 / .22$ \\
\hline Partner effect $\left(\mathrm{a}_{\mathrm{P} 1} ; \mathrm{a}_{\mathrm{P} 2}\right)$ & .05 & .03 & .162 & $.06 / .05$ & $-.02 / .11$ \\
\hline \multicolumn{6}{|l|}{ Avoidance } \\
\hline \multicolumn{6}{|l|}{$\mathrm{H} 2 \mathrm{a}$} \\
\hline Actor effect $\left(\mathrm{b}_{\mathrm{A} 1} ; \mathrm{b}_{\mathrm{A} 2}\right)$ & -.09 & .02 & $<.001$ & $-.18 /-.15$ & $-.04 /-.13$ \\
\hline Partner effect $\left(b_{\mathrm{P} 1} ; b_{\mathrm{P} 2}\right)$ & -.01 & .02 & .697 & $-.02 /-.02$ & $-.05 / .04$ \\
\hline$R_{\text {Women }}^{2} / R_{\text {Men }}^{2}$ & $.05 / .04$ & & & & \\
\hline \multicolumn{6}{|c|}{ Partner's stress communication (second model) } \\
\hline \multicolumn{6}{|c|}{ Approach } \\
\hline \multicolumn{6}{|l|}{$\mathrm{H} 2 \mathrm{~b}$} \\
\hline Actor effect $\left(\mathrm{a}_{\mathrm{A} 1} ; \mathrm{a}_{\mathrm{A} 2}\right)$ & .07 & .04 & .049 & $.18 / .17$ & $-.00 / .14$ \\
\hline \multicolumn{6}{|l|}{$\mathrm{H} 2 \mathrm{c}$} \\
\hline Partner effect $\left(\mathrm{a}_{\mathrm{P} 1} ; \mathrm{a}_{\mathrm{P} 2}\right)$ & .14 & .04 & $<.001$ & $.06 / .05$ & $.06 / .21$ \\
\hline \multicolumn{6}{|l|}{ Avoidance } \\
\hline \multicolumn{6}{|l|}{$\mathrm{H} 2 \mathrm{~b}$} \\
\hline Actor effect $\left(\mathrm{b}_{\mathrm{A} 1} ; \mathrm{b}_{\mathrm{A} 2}\right)$ & .05 & .02 & .052 & $.07 / .08$ & $-.00 / .09$ \\
\hline \multicolumn{6}{|l|}{$\mathrm{H} 2 \mathrm{c}$} \\
\hline Partner effect $\left(\mathrm{b}_{\mathrm{P} 1} ; \mathrm{b}_{\mathrm{P} 2}\right)$ & -.09 & .02 & $<.001$ & $-.13 /-.17$ & $-.04 /-.13$ \\
\hline$R_{\text {Women }}^{2} / R_{\text {Men }}^{2}$ & $.05 / .03$ & & & & \\
\hline \multicolumn{6}{|c|}{ Own dyadic coping (first model) } \\
\hline \multicolumn{6}{|l|}{ Approach } \\
\hline \multicolumn{6}{|l|}{$\mathrm{H} 3 \mathrm{a}$} \\
\hline Actor effect $\left(\mathrm{a}_{\mathrm{A} 1} ; \mathrm{a}_{\mathrm{A} 2}\right)$ & .16 & .02 & $<.001$ & $.29 / .31$ & $.12 / .20$ \\
\hline Partner effect $\left(\mathrm{a}_{\mathrm{P} 1} ; \mathrm{a}_{\mathrm{P} 2}\right)$ & .08 & .02 & $<.001$ & $.14 / .15$ & $.04 / .12$ \\
\hline \multicolumn{6}{|l|}{ Avoidance } \\
\hline \multicolumn{6}{|l|}{$\mathrm{H} 3 \mathrm{a}$} \\
\hline Actor effect $\left(b_{\mathrm{A} 1} ; b_{\mathrm{A} 2}\right)$ & -.02 & .01 & .174 & $-.05 /-.05$ & $.01 /-.04$ \\
\hline Partner effect $\left(b_{\mathrm{P} 1} ; b_{\mathrm{P} 2}\right)$ & -.03 & .01 & .026 & $-.08 /-.09$ & $-.00 /-.05$ \\
\hline$R_{\text {Women }}^{2} / R_{\text {Men }}^{2}$ & $.11 / .12$ & & & & \\
\hline Partner's dyadic coping (sec & d model) & & & & \\
\hline Approach & & & & & \\
\hline $\mathrm{H} 3 \mathrm{~b}$ & & & & & \\
\hline Actor effect $\left(\mathrm{a}_{\mathrm{A} 1} ; \mathrm{a}_{\mathrm{A} 2}\right)$ & .17 & .03 & $<.001$ & $.21 / .27$ & $.12 / .22$ \\
\hline $\mathrm{H} 3 \mathrm{c}$ & & & & & \\
\hline Partner effect $\left(\mathrm{a}_{\mathrm{P} 1} ; \mathrm{a}_{\mathrm{P} 2}\right)$ & .15 & .03 & $<.001$ & $.20 / .24$ & $.10 / .20$ \\
\hline
\end{tabular}


Table 3 (continued)

\begin{tabular}{llllll}
\hline Model & Unstand. estimate & $\mathrm{SE}$ & $p$ & $\begin{array}{l}\text { Stand. estimate } \\
\text { women/men }\end{array}$ & $\mathrm{CI}_{95}$ lower/upper \\
\hline $\begin{array}{l}\text { Avoidance } \\
\mathrm{H} 3 \mathrm{~b}\end{array}$ & & & & & \\
$\quad$ Actor effect $\left(\mathrm{b}_{\mathrm{A} 1} ; \mathrm{b}_{\mathrm{A} 2}\right)$ & -.05 & .02 & .003 & $-.11 /-.12$ & $-.02 /-.08$ \\
$\mathrm{H} 3 \mathrm{c}$ & & & & & \\
$\quad \begin{array}{l}\text { Partner effect }\left(\mathrm{b}_{\mathrm{P} 1} ; \mathrm{b}_{\mathrm{P} 2}\right) \\
R_{\text {Women }} 2 / R_{\text {Men }}{ }^{2}\end{array}$ & -.04 & .02 & .011 & $-.08 /-.11$ & $-.01 /-.07$ \\
\hline
\end{tabular}

$R^{2}$ variance explained, $S E$ standard error, $p$ level of significance, $i$ standardized estimates differ for female and male partners since unstandardized path coefficients have been set equal to each other but not variances and residual variances; $\mathrm{CI}_{95} 95 \%$ confidence interval of unstandardized coefficients, $H$ hypotheses

relationship outcomes, are associated with the experience of relationship problems and the perceived quality of the interaction between partners. These findings indicate that the approach-avoidance distinction is important for understanding specific interactions between spouses and relationship quality in general. Below we discuss our findings in more detail.

\section{Relation of approach-goals to relationship problems, stress communication and dyadic coping}

Our findings indicate that approach-oriented people experience fewer relationship problems, communicate their stress and negative feelings to their partners more often, provide more dyadic coping, and perceive their partners as being more disclosing and more supportive. They also receive better ratings from their partners regarding their stress communication and their dyadic coping behaviours. Moreover, partners of approach-oriented people experience fewer relationship problems and provide more dyadic coping to their spouses.

This consistent picture throughout the different models may be explained by the regulation strategies of approachmotivated people. Individuals with strong approach goals focus on rewarding aspects and give more weight to positive information and positive feelings regarding their relationship (e.g., Gable and Poore 2008). They specifically concentrate on aspects that might strengthen the bond of their relationship. This focus may buffer the experience of relationship problems, because difficulties do not outweigh other, more positive properties of the partner or the relationship. The lack of a negative reaction on the part of an approach-oriented person to a possible relationship problem might therefore prevent a negative spiral of conflict in the couple. Furthermore, the regulation strategies of people with strong approach goals might reflect their stronger intention to use communication and their perception of their partner's communication to bond and to create closeness and mutual interest. These individuals perceive their partner as being more disclosing, which might reflect their heightened sensitivity to their partner's attempt to share personal information. Accordingly, partner ratings point in the same direction as the self-reports of stress communication, which might indicate that more approach-oriented people not only perceive themselves as being more disclosing, but may actually be more self-disclosing.

Another advantage of communicating stress to the partner might be that it enables the partner to show support to his/her spouse. For approach-oriented people, providing, or being asked to provide, dyadic coping might be perceived as beneficial to the relationship and this leads to heightened mutual support within the relationship. Accordingly, partner evaluations point in the same direction as the self-evaluations of one's own dyadic coping, which indicates that more approach-oriented people not only perceive themselves as being more supportive but actually behave in more supportive ways. All of these aspects of relationship quality, which are positively related to approach goal orientation in partners, have been shown to be crucial for relationship functioning and the enhancement and maintenance of healthy and stable relationships (Hahlweg and Richter 2010; Karney and Bradbury 1995; Randall and Bodenmann 2009).

\section{Relation of avoidance-goals to relationship-related stress, stress communication and dyadic coping}

Our findings further indicate that avoidance-oriented people report more relationship problems, report communicating their stress and negative feelings less often to their partners, and report perceiving their partners as being less supportive. They also receive poorer ratings from their partners regarding stress communication and dyadic coping behaviour.

This might be explained by the regulation strategies of avoidance-oriented people. Their focus on negative outcomes or events is likely to heighten their perception of relationship problems. Avoidance-oriented spouses might display a heightened vigilance for problems within their 
relationship, which might explain why these spouses reported experiencing more relationship problems. This vigilance for negative information might also explain the results regarding the process of stress communication. Sharing personal information involves the possibility of embarrassment and being rejected or judged by one's partner (Fisher et al. 1988; Harris et al. 1999). From an avoidance-oriented person's point of view, one's own stress communication as well as the partner's stress communication might be perceived as a threat to the self and to the relationship because it sheds light on difficulties. To communicate stress to the partner is therefore interpreted as being neither beneficial nor comforting. On the contrary, avoidance-oriented people seem to hold back their stress in order to protect the stability of their relationship. Nothing bad is meant to happen to the relationship-therefore, negative information is withheld from the partner. This is confirmed by their partners, who perceive their avoidanceoriented spouses as being less disclosing, i.e. less communicative about stress.

Interestingly, the more avoidance-oriented people are, the more disclosing they perceive their partners as being. This finding might be one explanation why avoidance goals impair relationship satisfaction (see e.g., Impett et al. 2010). An avoidance-oriented spouse may withhold his or her own stressful events or feelings for the sake of not endangering the stability of the relationship, but at the same time may display a heightened sensitivity towards such information when communicated by the partner. This leads to an imbalance with regard to perceived disclosure of stress, which might additionally lead to higher negativity towards the partner and less relationship satisfaction (Utne et al. 1984; Walster et al. 1978).

Lastly, partners of people with avoidance goals seem less likely to provide dyadic coping. One explanation might be that the threshold for helping or offering assistance might be higher because helping a partner who has not asked for help is difficult and could even be interpreted as offensive (see e.g., styles of social control tactics used by spouses to increase health-enhancing behaviors in their partners; Lewis and Butterfield 2007; Lewis and Rook 1999), making it more unlikely that help will be offered in the future. Even the support of skilled partners might be experienced as intrusive and counterproductive by a stressed person, and unskilled partners' comforting behaviour might even exacerbate rather than reduce frustration and anger (Bodenmann et al. 2010).

Furthermore, given the assumption that dyadic coping, i.e., providing support to the partner, is seen as a form of behaviour that requires a high degree of competence (couple programs teach spouses specific coping skills; see e.g., Bodenmann and Shantinath 2004) - it is possible that individuals with avoidance goals focus on avoiding the demonstration of inferior ability and incompetence (Elliot and Church 1997; Elliot and McGregor 1999). Avoidanceoriented people may not consider themselves to be competent enough to handle situations in which they have to assist or provide emotional support to their partners, and therefore avoid providing dyadic coping as a precaution against a possible danger to the relationship. Finally, the focus on negative possibilities in avoidance goals leads to aversive psychological processes, including distracting thoughts, experiencing anxiety, or feeling compelled to escape from the goal-relevant situation, and these processes consume resources (Derryberry and Reed 2002; Elliot and McGregor 1999; Oertig et al. 2013). This might lead either to a lack of resources being available for dyadic coping or a lack of resources for recognizing situations which demand the provision of support.

The negative relationship between avoidance goals and these important aspects of relationship quality may already impair relationship quality and, ultimately, relationship satisfaction. However, our data revealed two more aspects that may enhance negativity within close relationships: First, avoidance-oriented people communicate less stress to their partner, while perceiving their partner as being more disclosing. Second, avoidance-oriented people receive less dyadic coping from their partners (partnerreported), while not reporting that they themselves provide less dyadic coping. These divergent perceptions between oneself and one's partner may lead to feelings of inequality that are detrimental to the relationship (Utne et al. 1984; Walster et al. 1978).

\section{Limitations and future directions}

Notwithstanding its strengths, the following limitations of the study should be kept in mind when interpreting our findings. Despite the diversity of our sample, couples were relatively homogenous with respect to most of our variables. Especially for dyadic coping and relationship problems, the variance was far lower than we would expect in the population. On the other hand, limited variance leads to a more conservative testing, i.e., it is more difficult to obtain significant results, which might bolster our findings. Nonetheless, higher diversity within the data would be desirable in order to validate our findings. It would be especially interesting to examine whether the same pattern of results is found in unhappy couples, because it remains unclear from our data whether approach and avoidance goals bolster against or accelerate negativity within unhappy couples, especially over time.

The results are based on cross-sectional data, which, of course, do not allow any inferences to be drawn regarding causality. Even though we treated approach and avoidance goals as the predictor variable, it is also possible that relationship goal orientation is the consequence of relationship 
problems, lack of stress communication or dyadic coping skills. In long-term relationships, expectations of one's partner's behaviour may lead to the adoption of approach or avoidance goals. If one member of the couple is not very supportive (e.g., because of relationship problems or lack of skills) the other partner might adopt an avoidance attitude (avoidance-oriented cognitions and goals) in order to protect themselves or the relationship. Longitudinal data will provide more insights into the dynamics of approach and avoidance goals operating in relationships. Moreover, even though we discuss our findings as involving aspects of interpersonal behaviour, the data analysed in this study were based on self-reports and partner reports. However, our data revealed that reporting one's own behaviour was in line with the report given by the partner of approach- as well as avoidance-oriented people. This makes it unlikely that the effects depend solely on a biased self-report. More probably, these findings indicate that goal orientation is translated into behaviour that is perceivable by the partner. Nevertheless, to strengthen our supposition further studies are needed that include observational data on behavioural correlates of approach and avoidance goals and orientation. These data would probably expand our understanding of the influence of approach and avoidance relationship goals on behavioural processes in intimate relationships.

\section{Conclusion}

The present study widens the scope of previous research on relationship problems and stress in couples by offering an individual difference perspective that might help to answer the following questions: Who suffers from relationship problems, who communicates stress and who engages in dyadic coping? Indeed, partners' approach-avoidance goal orientations were consistently related to these core aspects of relationship functioning. According to McCrae and Costa (1996), personal (approach-avoidance) goals can be conceptualized as characteristic adaptations that constitute an individual's personality over and above basic, biologically founded tendencies (i.e., the Big Five). Unlike basic personality traits, goals are open to change and thus also provide an avenue for therapeutic interventions in couples (Grosse Holtforth et al. 2006). Moreover, the present study contributes to the existing literature by associating important aspects of relationship quality and individual differences in motivational orientation, thereby providing further indication that approach-avoidance goal orientation might be translated not only into cognitions and perception but also into behaviour. By integrating the concept of goal orientation into the research of relationship functioning, this study has provided some interesting evidence that may lead to a better understanding of how relationships work.
Funding This research has been funded by the Swiss National Science Foundation (SNSF: CRSI11_133004/1) to Guy Bodenmann, Veronika Brandstätter, Mike Martin, Fridtjof W. Nussbeck, and Thomas N. Bradbury.

\section{References}

Arbuckle, J. L. (2010). Amos (Version 20). Chicago, IL: SPSS.

Bodenmann, G. (1995). A systemic-transactional conceptualization of stress and coping in couples. Swiss Journal of Psychology, 54(1), 34-49.

Bodenmann, G. (1997). Dyadic coping: A systemic-transactional view of stress and coping among couples: Theory and empirical findings. European Review of Applied Psychology, 47(2), 137-141.

Bodenmann, G. (2005). Dyadic coping and its significance for marital functioning. In T. Revenson, K. Kayser \& G. Bodenmann (Eds.), Couples coping with stress: Emerging perspectives on dyadic coping (pp. 33-50). Washington, DC: APA.

Bodenmann, G. (2008). Dyadisches coping inventar (DCI). [Dyadic coping inventory]. Test manual. Bern: Huber \& Hogrefe Testverlag.

Bodenmann, G., \& Cina, A. (2005). Stress and coping among stablesatisfied, stable-distressed, and separated/divorced Swiss couples: A 5-year prospective longitudinal study. Journal of Divorce and Remarriage, 44(1-2), 71-89. doi:10.1300/J087v44n01_04.

Bodenmann, G., Meuwly, N., Bradbury, T. N., Gmelch, S., \& Ledermann, T. (2010). Stress, anger, and verbal aggression in intimate relationships: Moderating effects of individual and dyadic coping. Journal of Social and Personal Relationships, 27(3), 408-424. doi:10.1177/0265407510361616.

Bodenmann, G., Schär, M., \& Gmelch, S. (2008). Multi-dimensionaler Stressfragebogen für Paare (MDS-P). Unpublished Questionnaire. Zurich: University of Zurich.

Bodenmann, G., \& Shantinath, S. D. (2004). The Couples Coping Enhancement Training (CCET): A new approach to prevention of marital distress based upon stress and coping. Family Relations, 53(5), 477-484. doi:10.1111/j.0197-6664.2004.00056.x.

Butler, R. (2007). Teachers' achievement goal orientations and associations with teachers' help seeking: Examination of a novel approach to teacher motivation. Journal of Educational Psychology, 99(2), 241-252. doi:10.1037/0022-0663.99.2.241.

Carver, C. S., Sutton, S. K., \& Scheier, M. F. (2000). Action, emotion, and personality: Emerging conceptual integration. Personality and Social Psychology Bulletin, 26(6), 741-751. doi:10.1177/0146167200268008.

Cutrona, C. E. (2004). A psychological perspective: Marriage and the social provisions of relationships. Journal of Marriage and Family, 66(4), 992-999. doi:10.1111/j.0022-2445.2004.00070.x.

Derlega, V. J., Metts, S., Petronio, S., \& Margulis, S. T. (1993). Selfdisclosure. Newbury Park, CA: Sage.

Derryberry, D., \& Reed, M. A. (1994). Temperament and attention: Orienting toward and away from positive and negative signals. Journal of Personality and Social Psychology, 66(6), 1128-1139. doi:10.1037//0022-3514.66.6.1128.

Derryberry, D., \& Reed, M. A. (2002). Anxiety-related attentional biases and their regulation by attentional control. Journal of Abnormal Psychology, 111(2), 225-236. doi:10.1037//0021-843x.111.2.225.

Elliot, A. J. (2008). Handbook of approach and avoidance motivation. New York: Psychology Press.

Elliot, A. J., \& Church, M. A. (1997). A hierarchical model of approach and avoidance achievement motivation. Journal of Personality and Social Psychology, 72(1), 218-232. 
Elliot, A. J., Gable, S. L., \& Mapes, R. R. (2006). Approach and avoidance motivation in the social domain. Personality and Social Psychology Bulletin, 32(3), 378-391. doi:10.1177/0146167205282153.

Elliot, A. J., \& McGregor, H. A. (1999). Test anxiety and the hierarchical model of approach and avoidance achievement motivation. Journal of Personality and Social Psychology, 76(4), 628-644. doi:10.1037//0022-3514.76.4.628.

Elliot, A. J., \& Sheldon, K. M. (1997). Avoidance achievement motivation: A personal goals analysis. Journal of Personality and Social Psychology, 73(1), 171-185. doi:10.1037//0022-3514.73.1.171.

Elliot, A. J., \& Thrash, T. M. (2002). Approach-avoidance motivation in personality: Approach and avoidance temperaments and goals. Journal of Personality and Social Psychology, 82(5), 804-818. doi:10.1037//0022-3514.82.5.804.

Elliot, A. J., Thrash, T. M., \& Murayama, K. (2011). A longitudinal analysis of self-regulation and well-being: Avoidance personal goals, avoidance coping, stress generation, and subjective well-being. Journal of Personality, 79(3), 643-674. doi:10.1111/j.1467-6494.2011.00694.x.

Falconier, M. K., Jackson, J., Hilpert, J., \& Bodenmann, G. (2015). Dyadic coping and relationship satisfaction: A meta-analysis. Clinical Psychology Review, 42, 28-46.

Fisher, J. S., Goff, B. A., Nadler, A., \& Chinsky, J. M. (1988). Social psychological influences on help seeking and support from peers. In B. H. Gottlieb (Ed.), Marshaling social support: Formats, processes, and effects. Newbury Park, CA: Sage.

Gable, S. L. (2006). Approach and avoidance social motives and goals. Journal of Personality, 74(1), 175-222. doi:10.1111/j.1467-6494.2005.00373.x.

Gable, S. L., \& Berkman, E. T. (2008). Making connections and avoiding loneliness: Approach and avoidance social motives and goals. In A. J. Elliot (Ed.), Handbook of approach and avoidance motivation (pp. 203-216). New York: Psychology Press.

Gable, S. L., \& Impett, E. A. (2012). Approach and avoidance motives and close relationships. Social and Personality Psychology Compass, 6(1), 95-108. doi:10.1111/j.1751-9004.2011.00405.x.

Gable, S. L., \& Poore, J. (2008). Which thoughts count? Algorithms for evaluating satisfaction in relationships. Psychological Science, 19(10), 1030-1036. doi:10.1111/j.1467-9280.2008.02195.x.

Gable, S. L., Reis, H. T., \& Elliot, A. J. (2000). Behavioral activation and inhibition in everyday life. Journal of Personality and Social Psychology, 78(6), 1135-1149. doi:10.1037//0022-3514.78.6.1135.

Gottman, J. M. (1994). What predicts divorce: The relationships between marital processes and marital outcome. Hillsdale, NJ: Erlbaum.

Gray, J. A. (1990). Brain systems that mediate both emotion and cognition. Cognition and Emotion, 4(3), 269-288. doi:10.1080/02699939008410799.

Grosse Holtforth, M., Grawe, K., \& Castonguay, L. G. (2006). Predicting a reduction of avoidance motivation in psychotherapy: Toward the delineation of differential processes of change operating at different phases of treatment. Psychotherapy Research, 16(5), 626-630. doi:10.1080/10503300600608215.

Hahlweg, K., \& Richter, D. (2010). Prevention of marital instability and distress: Results of an 11-year longitudinal follow-up study. Behaviour Research and Therapy, 48(5), 377-383. doi:10.1016/j. brat.2009.12.010.

Hancock, G. R. (2006). Power analysis in covariance structure modeling. In R. C. Serlin (Series Ed.), G. R. Hancock \& R. O. Mueller (Eds.), Structural equation modeling: A second course (pp. 69-115). Greenwich, CT: Information Age.

Harris, S. M., Dersch, C. A., \& Mittal, M. (1999). Look who's talking: Measuring self-disclosure in MFT. Contemporary Family Therapy, 21(3), 405-415. doi:10.1023/A:1021968517320.
Herzberg, P. Y. (2013). Coping in relationships: The interplay between individual and dyadic coping and their effects on relationship satisfaction. Anxiety, Stress \& Coping: An International Journal, 26, 136-153. doi:10.1080/10615806.2012.6 55726.

Higgins, E. T. (2011). Beyond pleasure and pain: How motivation works. New York: Oxford University Press.

Impett, E. A., Gordon, A. M., Kogan, A., Oveis, C., Gable, S., \& Keltner, D. (2010). Moving toward more perfect unions: Daily and long-term consequences of approach and avoidance goals in romantic relationships. Journal of Personality and Social Psychology, 99(6), 948-963. doi:10.1037/a0020271.

Impett, E. A., Strachman, A., Finkel, E., \& Gable, S. (2008). Maintaining sexual desire in intimate relationships: The importance of approach goals. Journal of Personality and Social Psychology, 94(5), 808-823. doi:10.1037/0022-3514.94.5.808.

Karney, B. R., \& Bradbury, T. N. (1995). The longitudinal course of marital quality and stability: A review of theory, method, and research. Psychological Bulletin, 118(1), 3-34. doi:10.1037/0033-2909.118.1.3.

Kenny, D. A., Kashy, D. A., \& Cook, W. L. (2006). Dyadic data analysis. New York: Guilford Press.

Kuster, M., Bernecker, K., Backes, S., Brandstaetter, V., Nussbeck, F. W., Bradbury, T. N., ... Bodenmann, G (2015). Avoidance orientation and the escalation of negative communication in intimate relationships. Journal of Personality and Social Psychology, 109(2), 262-275. doi:10.1037/pspi0000025.

Landis, M., Bodenmann, G., Bradbury, T. N., Brandstätter, V., Peter-Wight, M., Backes, S., \& Nussbeck, F. W. (2014). Commitment and dyadic coping in long-term relationships. Journal of Gerontopsychology and Geriatric Psychiatry, 27, 139-149. doi:10.1024/1662-9647/a000112.

Lewis, M. A., \& Butterfield, R. M. (2007). Social control in marital relationships: Effect of one's partner on health behaviors. Journal of Applied Social Psychology, 37(2), 298-319. doi:10.1111/j.0021-9029.2007.00161.x.

Lewis, M. A., \& Rook, K. S. (1999). Social control in personal relationships: Impact on health behaviors and psychological distress. Health Psychology, 18(1), 63-71. doi:10.1037//0278-6133.18.1.63.

McCrae, R. R., \& Costa, P. T. j (1996). Toward a new generation of personality theories: Theoretical contexts for the five-factor model. In J. S. Wiggins (Ed.), The five-factor model of personality: Theoretical perspectives (pp. 51-87). New York: Guilford.

Muthén, L. K., \& Muthén, B. O. (2002). How to use a Monte Carlo study to decide on sample size and determine power. Structural Equation Modeling: A Multidisciplinary Journal, 9, 599-620. doi:10.1207/S15328007SEM0904_8.

Oertig, D., Schüler, J., Schnelle, J., Brandstätter, V., Roskes, M., \& Elliot, A. J. (2013). Avoidance goal pursuit depletes selfregulatory resources. Journal of Personality, 81(4), 365-375. doi:10.1111/Jopy.12019.

Papp, L. M., \& Witt, N. L. (2010). Romantic partners' individual coping strategies and dyadic coping: Implications for relationship functioning. Journal of Family Psychology, 24(5), 551-559. doi:10.1037/A0020836.

Randall, A. K., \& Bodenmann, G. (2009). The role of stress on close relationships and marital satisfaction. Clinical Psychology Review, 29(2), 105-115. doi:10.1016/j.cpr.2008.10.004.

Reis, H. T., \& Patrick, B. C. (1996). Attachment and intimacy: Component processes. In E. T. Higgins \& A. W. Kruglanski (Eds.), Social psychology: Handbook of basic principles (pp. 523-563). New York: Guilford Press.

Roth, S., \& Cohen, L. J. (1986). Approach, avoidance, and coping with stress. American Psychologist, 41(7), 813-819. doi:10.1037//0003-066x.41.7.813. 
Sprecher, S., \& Hendrick, S. S. (2004). Self-disclosure in intimate relationships: Associations with individual and relationship characteristics over time. Journal of Social and Clinical Psychology, 23(6), 857-877. doi:10.1521/jscp.23.6.857.54803.

Story, L. B., \& Bradbury, T. N. (2004). Understanding marriage and stress: Essential questions and challenges. Clinical Psychology Review, 23(8), 1139-1162. doi:10.1016/j.cpr.2003.10.002.

Strachman, A., \& Gable, S. L. (2006). What you want (and do not want) affects what you see (and do not see): Avoidance social goals and social events. Personality and Social Psychology Bulletin, 32(11), 1446-1458. doi:10.1177/0146167206291007.

Updegraff, J. A., Gable, S. L., \& Taylor, S. E. (2004). What makes experiences satisfying? The interaction of approachavoidance motivations and emotions in well-being. Journal of Personality and Social Psychology, 86(3), 496-504. doi:10.1037/0022-3514.86.3.496.
Utne, M. K., Hatfield, E., Traupmann, J., \& Greenberger, D. (1984). Equity, marital satisfaction, and stability. Journal of Social and Personal Relationships, 1, 323-332.

Walster, E., Walster, G. W., \& Berscheid, E. (1978). Equity: Theory and research. Boston: Allyn \& Bacon.

Woodin, E. M. (2011). A two-dimensional approach to relationship conflict: Meta-analytic findings. Journal of Family Psychology, 25, 325-335. doi:10.1037/a0023791.

Zemp, M., Bodenmann, G., Backes, S., Sutter-Stickel, D., \& Bradbury, T. N. (2016a). Positivity and negativity in interparental conflict: Implications for children. Swiss Journal of Psychology, 75, 167-173.

Zemp, M., Bodenmann, G., Backes, S., Sutter-Stickel, D., \& Revenson, T. A. (2016b). The importance of parents' dyadic coping for children. Family Relations, 65, 275-286. 